\title{
A Rare Glimpse into the Past of the Anthrax Pathogen Bacillus anthracis
}

\author{
Peter Braun ${ }^{1}$, Mandy Knüpfer ${ }^{1}$, Markus Antwerpen ${ }^{1}$, Dagmar Triebel ${ }^{2}(1)$ and Gregor Grass ${ }^{1, *}$ \\ 1 Bundeswehr Institute of Microbiology (IMB), 80937 Munich, Germany; peter3braun@bundeswehr.org (P.B.); \\ mandyknuepfer@bundeswehr.org (M.K.); markusantwerpen@bundeswehr.org (M.A.) \\ 2 Bavarian Natural History Collections (SNSB—Botanische Staatssammlung München), 80638 Munich, \\ Germany; triebel@snsb.de \\ * Correspondence: gregorgrass@bundeswehr.org; Tel.: +49-992692-3981
}

Received: 28 January 2020; Accepted: 19 February 2020; Published: 21 February 2020

\begin{abstract}
The bacterium Bacillus anthracis is the causative agent of the zoonotic disease anthrax. While genomics of extant $B$. anthracis isolates established in-depth phylogenomic relationships, there is scarce information on the historic genomics of the pathogen. Here, we characterized the oldest documented B. anthracis specimen. The inactive 142-year-old material originated from a bovine diseased in Chemnitz (Germany) in 1878 and is contemporary with the seminal studies of Robert Koch on B. anthracis. A specifically developed isolation method yielded high-quality DNA from this specimen for genomic sequencing. The bacterial chromosome featuring 242 unique base-characters placed it into a major phylogenetic clade of B. anthracis (B.Branch CNEVA), which is typical for central Europe today. Our results support the notion that the CNEVA-clade represents part of the indigenous genetic lineage of $B$. anthracis in this part of Europe. This work emphasizes the value of historic specimens as precious resources for reconstructing the past phylogeny of the anthrax pathogen.
\end{abstract}

Keywords: anthrax; Bacillus anthracis; historic specimen; genome-sequencing; phylogeny

\section{Introduction}

For notorious pathogens such as Yersinia pestis (plague) or Mycobacterium tuberculosis (tuberculosis), there is ample information on the historic phylogeography of the pathogens from human remains. For instance, the oldest molecular evidence for historic plague from Sweden is 4900 years old [1]. In contrast, for Bacillus anthracis, the bacterium causing the zoonotic disease anthrax, our knowledge on its historic phylogeny hardly reaches back more than a hundred years. Though Louis Pasteur performed his famous public anthrax vaccination experiment in 1881, the Collection de l'Institut Pasteur (CIP) only initiated the collection of bacterial strains in 1892 [2]. These strains, however, have been cultured ever since, and thus likely have accumulated recent genetic changes. Conversely, dead specimens or bacteria from human remains are evolutionary inert.

Anthrax has plagued humans and both wild and domestic animals for hundreds-possibly many thousands-of years [3]. Even today, the pathogen is rampant in numerous countries on all continents except Antarctica [4]. Only a few countries have managed, through governmental and institutional vaccination campaigns, disease reporting and safe cadaver disposal programs to all but eradicate anthrax outbreaks today. Even Germany, which has seen very limited minor animal outbreaks recently in 2009, 2012, and 2014 [5], had been stricken by the disease only a century ago. From 1912 to 1932 (no data for 1926), 2518 people became infected, of which 431 died. Within the same time period, about 90,000 domestic animals fell from the disease [6]. Within that time occurred the infamous "Baron von Rosen espionage incident" involving sugar lumps allegedly laced with the anthrax pathogen aimed at sabotaging allied horse-powered war-support-lines in $1917[7,8]$. While there is a large number of 
live historical B. anthracis isolates in culture, the oldest one mentioned in literature is from approx. 1890 [9] but lacks associated metadata. Thus, its origin remains elusive. Finally, B. anthracis has recently been isolated from excavation sites at the permafrost zone of northern Russia [10]. If these isolates, however, indeed originated from thousands-of-years-old cadavers devoid of any vegetative episodes of germinating spores and re-sporulating bacteria remains debatable. Also, it cannot be excluded that spores from younger outbreaks have contaminated deeper, older soil horizons. Nevertheless, with large permafrost areas thawing, we might see reemerging anthrax in high latitudes [10].

Historic, fixed specimens of $B$. anthracis on glass slides have attracted surprisingly little interest as valuable means for expanding our knowledge on the anthrax pathogen diversity. Published works comprise information from relatively young samples only: a couple of years old from Jordan [11], up to 30 years old from Zambia [12], or about 35-year-old paraffin-embedded samples from the former Soviet Union [13].

Thus, to date, there is no described bona fide historical genome of $B$. anthracis. In this report, we characterized the oldest documented B. anthracis genome from a 142-year-old historic microscopic slide.

\section{Materials and Methods}

\subsection{B. anthracis Strains, Growth Conditions, and Extraction of DNA from Inactivated Culture Material}

All strains (chromosomes) used in this study are listed in Supplementary Table S1. B. anthracis cultures from our strain collections were cultivated in our biosafety level 3 laboratory on blood agar and then chemically inactivated before further use [14]. DNA was isolated using MasterPure ${ }^{\mathrm{TM}}$ Gram Positive DNA Purification kit (Lucigen, Middleton, WI, USA) and DNA concentrations were quantified using the Qubit dsDNA HS Assay Kit (Thermo Fisher Scientific, Dreieich, Germany) according to the manufacturers' protocols. DNA preparations were stored at $-20{ }^{\circ} \mathrm{C}$ until further use.

\subsection{Microscopic Evaluation of the Historical B. anthracis Specimen}

The original glass slide featuring a $B$. anthracis blood smear was carefully unwrapped from cover envelopes and examined by phase contrast microscopy (630-fold magnification) using a Leica DMi8 inverted light microscope (Leica Microsystems, Wetzlar, Germany).

\subsection{DNA Extraction from the Historical B. anthracis Blood Smear}

All manipulations related to sample Chemnitz 1878 (M-0290509 published in 1879 as no. 700 of the exsiccatae series [15]) were conducted in a laboratory not previously utilized to handle B. anthracis DNA in order to avoid contamination. A section of the blood smear was carefully removed using a sterile swab (Copan Nylon Floq Swab, Hain Life Science, Nehren, Germany) moistened with $100 \mu \mathrm{L}$ of sterile phosphate-buffered saline by slowly rotating the swab and sampling the surface in a zig-zag-like movement. The swab was air-dried for 15 min under a laminar air flow. The swab head was then cut off and placed into a 2-mL microcentrifuge tube. DNA was extracted using MasterPure ${ }^{\mathrm{TM}}$ Gram Positive DNA Purification kit (Lucigen, Middleton, WI, USA), using a modified protocol. Briefly, $150 \mu \mathrm{L}$ of TE buffer containing $1250 \mathrm{U}$ of Ready-Lyse lysozyme solution was added directly onto the swab head and incubated at $37^{\circ} \mathrm{C}$ for $60 \mathrm{~min}$. To this, $1 \mu \mathrm{L}$ of proteinase $\mathrm{K}(50 \mu \mathrm{g} / \mu \mathrm{L})$ diluted into $150 \mu \mathrm{L}$ of Gram-positive lysis solution was added. The tube was then incubated at $65{ }^{\circ} \mathrm{C}$ for $15 \mathrm{~min}$ at $900 \mathrm{rpm}$, briefly vortexed every $5 \mathrm{~min}$. After placing the sample on ice for $5 \mathrm{~min}$, the liquid and the swab head were transferred to a QIAshredder spin column (Qiagen, Hilden, Germany) and centrifuged at 14,000 rpm for $2 \mathrm{~min}$. The swab head was discarded and $175 \mu \mathrm{L}$ of 'MPC' Protein Precipitation Reagent was added to the flow-through. After vortexing, the debris was pelleted by centrifugation at $4{ }^{\circ} \mathrm{C}$ for $10 \mathrm{~min}$ at $14,000 \mathrm{rpm}$ in a microcentrifuge. The supernatant was transferred to a clean microcentrifuge tube. To this, $5 \mu \mathrm{L}$ of Roti-Pink (Carl Roth, Karlsruhe, Germany), $10 \mu \mathrm{L}$ of glycogen solution ( $5 \mathrm{mg} / \mathrm{mL}$, Carl Roth, Karlsruhe, Germany), and $500 \mu \mathrm{L}$ of isopropanol (Carl Roth, Karlsruhe, 
Germany) was added and gently mixed by inverting the tube $30-40$ times. DNA was pelleted by centrifugation at $4{ }^{\circ} \mathrm{C}$ for $10 \mathrm{~min}$ at $14,000 \mathrm{rpm}$ in a microcentrifuge. The DNA pellet was washed twice with $200 \mu \mathrm{L} 70 \%$ ethanol. After removing all of the residual ethanol, the DNA was resuspended in $50 \mu \mathrm{L}$ TE buffer and stored at $-20{ }^{\circ} \mathrm{C}$ until further use.

\subsection{Whole Genome Sequencing and Data Analysis—Single Nucleotide Polymorphism Calling}

From total DNA, an Illumina-compatible library was prepared (NEBNext ${ }^{\circledR}$ Ultra $^{\mathrm{TM}}$ II DNA Library Prep Kit, NEB, Frankfurt am Main, Germany) and sequenced on a MiSeq instrument (Illumina, San Diego, CA, USA) using MiSeq V3-chemistry. High-quality paired-end reads were assembled de novo using an in-house script based on SPAdes assembler [16] and Pilon [17] for correcting genome-assembly. In order to exclude age-related DNA-sequencing artifacts and to avoid incorrect conclusions, the genome sequence was curated manually as follows: First, obtained scaffolds (software BWA-SW [18]) were mapped to B. anthracis strain BF-1, a close genetic neighbor. Regions not covered by any reads were excluded from the consensus sequence. Second, BWA-mem was used to remap reads to the ordered contigs. Third, for eliminating ambiguous base positions, mpileup (software-package SAMtools [19]) was used with standard parameters. All ambiguous positions ( $n=9326$; i.e., $0.17 \%$ of the chromosome) were masked with " $\mathrm{N}$ " in the corresponding consensus-fasta-file. This final curated sequence was used for further comparative analyses. All data generated and analyzed during this study are included in this published article, its supplementary information files, or are publicly available in the NCBI Sequence Read Archive (SRA) repository (Bioproject PRJNA309927).

For multiple chromosome-wide SNP-comparison of B. anthracis, the Parsnp tool (Harvest Suite) was used [20]. For this, representative B. anthracis chromosomes from public databases (Supplementary Table S1) and newly sequenced chromosomes Chemnitz 1878, Tyrol 3520 and 6282 were aligned (Parsnp parameters $-\mathrm{c}-\mathrm{e}-\mathrm{u}-\mathrm{C}$ 1000) using B. anthracis Ames Ancestor reference chromosome (NC_007530) as phylogenetic outgroup.

Called SNPs were extracted into a multi-isolate-vcf file using the HarvestTools (version 1.0) from the same software suite [20]. To enhance data quality, closely adjacent SNPs with a distance of less than $10 \mathrm{bp}$ as well as positions harboring undefined nucleotides (" $\mathrm{N}$ ") were removed. This curated vcf-file was used as an input file in the HarvestTools to compile a FASTA-file comprising the concatenated SNPs of the investigated chromosome set as multiple-sequence alignment.

This concatenated sequence information was used to infer and analyze a maximum likelihood tree-based phylogeny in MEGA 7 [21,22]. SNPs found within the analyzed B. anthracis chromosomes are summarized in Supplementary Table S2. A minimum spanning tree was computed in BioNumerics 6.6 (Applied Maths, Sint-Martens-Latem, Belgium) from the vcf SNP-file (in binary format) as input and manually edited for style.

\section{Results and Discussion}

\subsection{Characterization of a Glass Slide Specimen Labeled B. anthracis from 1878.}

The 142-year-old microscopic slide featured an infected blood specimen from the Bavarian Natural History Collections SNSB—Botanische Staatssammlung München (Germany). It was rediscovered during an inventory in 2018. The slide envelope was orderly labeled, providing information on the responsible veterinarian and the time and geographic location of the diseased bovine from which the blood smear was taken (Figure 1a). A veterinarian named Dr. O. E. R. Zimmermann prepared the smear from infected bovine blood on a glass slide in 1878 (Figure 1b), only two years after Robert Koch started systematic research on B. anthracis. Careful microscopic documentation of the specimen indicated rod-like structures among likely dried-up bovine blood cells and even possible nascent spores, supporting the claim B. anthracis was indeed possibly present (Figure 1c). 

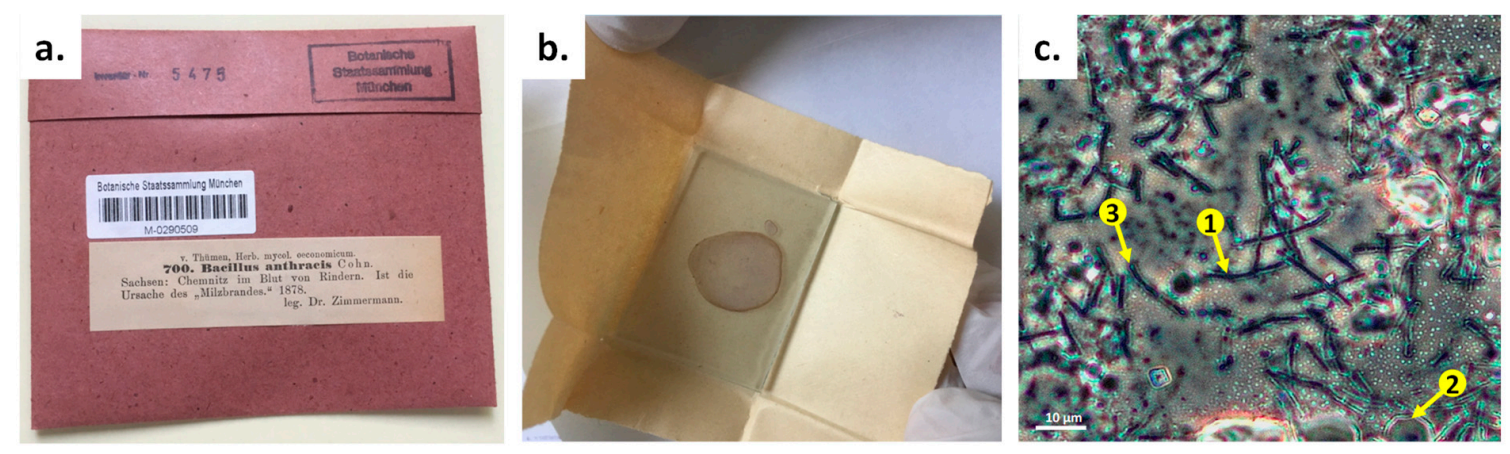

Figure 1. Initial characterization of a B. anthracis specimen from 1878. (a) The specimen with original label (translated from German: "Saxonia: Chemnitz in the blood of bovines. It is the source of 'anthrax'"). (b) Unpacking of the specimen, which was a glass slide paper-wrapped without any further glass cover. The red color from blood cells can still be identified. (c) Microscopic (phase-contrast) examination of the specimen. Arrow \#1 indicates rod-like structures, likely B. anthracis cells; arrow \#2 indicates possible bovine blood cells; and arrow \#3 indicates structures that resemble nascent endospores.

3.2. DNA Isolation from Specimen Chemnitz 1878 and Genome Sequencing Yielded a B. anthracis Genome Typical for Central Europe

Using an improved swab-based extraction method specifically developed for this need, we were able to isolate DNA from the historic specimen. Unexpectedly, the quality and quantity of the extracted DNA was sufficient for PCR and subsequent whole-genome sequencing. Thus, $2 \times 21,106,786$ reads were generated. Of the six Gb obtained, only about $2 \%(117,288,692$ bases $)$ were B. anthracis. The remaining $98 \%$ reads were of other bacterial (e.g., Cutibacterium sp.), bovine, or human $(6,590,587$ reads; $31 \%)$ origin. The latter likely reflecting repeated contact with museum staff during the last $100+$ years of storage, because the slide was not glass-covered.

Genomic in silico analysis revealed that the chromosomal B. anthracis PCR-marker dhp61 was present as well as both virulence plasmids pXO1 and pXO2. Canonical SNP-typing phylogenetically placed the historic genome, which we named Chemnitz 1878, within the B.Br.CNEVA clade of B. anthracis [23]. Next, we inferred the phylogenetic placement of the Chemnitz 1878 chromosome within the B.Br.CNEVA clade of B. anthracis (Figure 2a).

The closest living relative was strain A46, isolated from a pig near Stuttgart (Germany), with a distance of 313 SNPs, though a more distant relative, cattle isolate BF-1 from Bavaria, was at 307 SNPs distance (Figure 2b). Isolates from central Europe (Austria, Switzerland, and Slovakia) were grouped to the same lineage). From these, strain Tyrol 4675 featured the most SNP differences to strain Chemnitz 1878 (386 SNPs; Figure 2b). B.Br.CNEVA strains from France grouped phylogenetically further away, forming several distinct sub-clusters within CNEVA canSNP group (Figure 2a). Notably, with new B.Br.CNEVA-genomes now available, there is a significant polytomy right at the base of the B.Br.CNEVA lineage (Figure 2a), contrary to what was reported before based on more limited information [9]. 


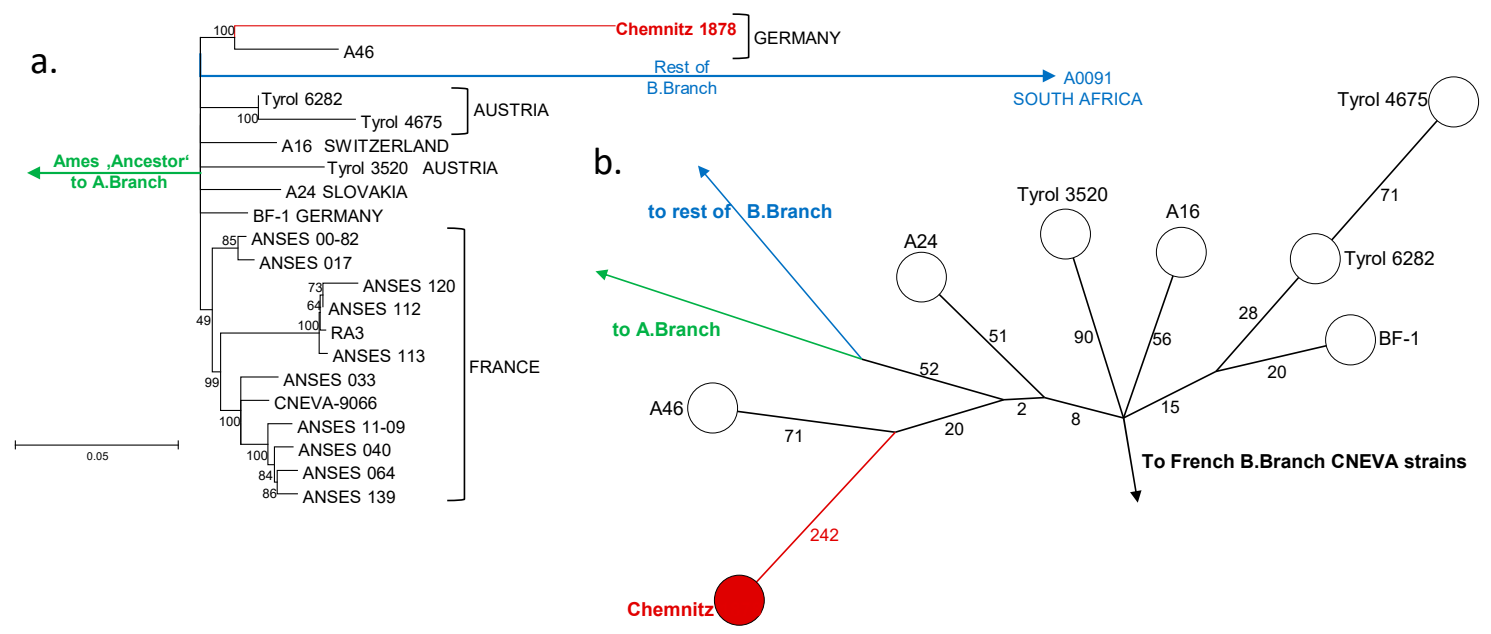

Figure 2. Phylogenetic placement of B. anthracis specimen Chemnitz 1878. (a) Rooted maximum likelihood tree derived from chromosomal Single Nucleotide Polymorphisms of Chemnitz 1878 and representative relatives ( 2450 chromosomal SNPs in total; bootstrap confidence-values based on 500 permutations). Isolate names and countries of origin are indicated at branch termini. The tree is rooted to the B. anthracis reference strain Ames 'Ancestor', which belongs to the A.Br.Ames clade. (b) Minimum spanning tree based on chromosomal SNPs showing strain Chemnitz 1878 alongside its closest relatives. Numbers next to branch-lines indicate SNPs separating nodes or strains.

While German B. anthracis strain collections feature a broad diversity of eight out of the twelve original B. anthracis canSNP-groups [23], recent data suggests B-branch isolates constituting the autochthonous population of the anthrax pathogen in countries from central [9] and northern [24] Europe, as well as from northwestern Asia (Russian Federation) [10]. Thus, from a bioforensics point of view, the isolation of a B.Br.CNEVA-type B. anthracis strain from a future outbreak would raise fewer concerns than would an isolate from a canSNP-group typical for a non-European origin.

\section{Conclusions}

This work emphasizes that historic specimen slides in mycological collections of herbaria, museums, and alike may constitute invaluable sources for reconstructing the historic phylogeny of the anthrax pathogen in countries in which the disease is all but eradicated today. Making this approach more broadly known would likely also avoid such mishaps (from a scientific point of view) as the one at the Chrysler Herbarium at Rutgers University in 2016 (https://news.illinois.edu/view/6367/350255). During a digitization project of historical samples, a 121-year-old specimen, an envelope labeled B. anthracis, was unearthed. Unfortunately, the envelope's content had been destroyed years before without further characterization.

Supplementary Materials: The following are available online at http://www.mdpi.com/2076-2607/8/2/298/s1: Table S1: Genome sequences accession numbers of newly sequenced and additional $B$. anthracis strains from publicly available databases; Table S2: Chromosome-wide binary SNP matrix of all analyzed B. anthracis chromosomes.

Author Contributions: Conceptualization: D.T., M.A., and G.G.; investigation: M.K. and P.B.; methodology: M.K., P.B., M.A., and G.G.; formal analysis and validation: M.A. and G.G.; resources: D.T., M.A., and G.G.; data curation: P.B., M.K., D.T., M.A., and G.G.; writing—original draft preparation: M.K., M.A., and G.G.; writing一review and editing: P.B., M.K., D.T., M.A., and G.G.; visualization: P.B., M.K., and G.G.; supervision and project administration: M.A. and G.G.; funding acquisition: M.A. and G.G. All authors have read and agreed to the published version of the manuscript.

Funding: This research was funded by funds from the Medical Biological Defense Research Program of the Bundeswehr Joint Medical Service. 
Acknowledgments: The authors thank Franz Allerberger, Austrian Agency for Health and Food Safety (Vienna, Austria) for the gift of Austrian B. anthracis strains. Thanks are due to Mathias Walter for support in bioinformatics analysis and script development; we also thank Linda Dobrzykowski and Josua Zinner for technical assistance and Ursula Rambold for identifying the historic anthrax material during a herbarium inventory.

Conflicts of Interest: The authors declare no conflict of interest. Opinions, interpretations, conclusions, and recommendations are those of the authors and are not necessarily endorsed by any governmental agency, department or other institutions. The funders had no role in the design of the study; in the collection, analyses, or interpretation of data; in the writing of the manuscript, or in the decision to publish the results.

\section{References}

1. Rascovan, N.; Sjogren, K.G.; Kristiansen, K.; Nielsen, R.; Willerslev, E.; Desnues, C.; Rasmussen, S. Emergence and spread of basal lineages of Yersinia pestis during the Neolithic decline. Cell 2019, 176, 295-305. [CrossRef] [PubMed]

2. Bennett, R.J.; Baker, K.S. Looking backward to move forward: The utility of sequencing historical bacterial genomes. J Clin. Microbiol 2019, 57. [CrossRef] [PubMed]

3. Dirckx, J.H. Virgil on anthrax. Am. J. Dermatopathol. 1981, 3, 191-195. [CrossRef]

4. World Health Organization. Anthrax in Humans and Animals, 4th ed.; WHO Press: Geneva, Switzerland, 2008.

5. Elschner, M.C.; Busch, A.; Schliephake, A.; Gaede, W.; Zuchantke, E.; Tomaso, H. High-quality genome sequence of Bacillus anthracis strain 14RA5914 isolated during an outbreak in Germany in 2014. Genome Announc. 2017, 5. [CrossRef]

6. Hunziker, S. Über gewerblichen Milzbrand. Ph.D. Thesis, University of Basel, Basel, Switzerland, $1939 ;$ p. 44.

7. Redmond, C.; Pearce, M.J.; Manchee, R.J.; Berdal, B.P. Deadly relic of the Great War. Nature 1998, 393, 747-748. [CrossRef] [PubMed]

8. Antwerpen, M.H.; Sahl, J.W.; Birdsell, D.; Pearson, T.; Pearce, M.J.; Redmond, C.; Meyer, H.; Keim, P.S. Unexpected relations of historical anthrax strain. MBio 2017, 8. [CrossRef]

9. Vergnaud, G.; Girault, G.; Thierry, S.; Pourcel, C.; Madani, N.; Blouin, Y. Comparison of French and worldwide Bacillus anthracis strains favors a recent, post-Columbian origin of the predominant North-American clade. PLoS ONE 2016, 11, e0146216. [CrossRef]

10. Timofeev, V.; Bahtejeva, I.; Mironova, R.; Titareva, G.; Lev, I.; Christiany, D.; Borzilov, A.; Bogun, A.; Vergnaud, G. Insights from Bacillus anthracis strains isolated from permafrost in the tundra zone of Russia. PLoS ONE 2019, 14, e0209140. [CrossRef]

11. Aqel, A.A.; Hailat, E.; Serrecchia, L.; Aqel, S.; Campese, E.; Vicari, N.; Fasanella, A. Molecular characterization of the circulating Bacillus anthracis in Jordan. Trop. Anim. Health Prod. 2015, 47, 1621-1624. [CrossRef]

12. Fasanella, A.; Serrecchia, L.; Chiaverini, A.; Garofolo, G.; Muuka, G.M.; Mwambazi, L. Use of canonical single nucleotide polymorphism (canSNPs) to characterize Bacillus anthracis outbreak strains in Zambia between 1990 and 2014. PeerJ 2018, 6, e5270. [CrossRef]

13. Sahl, J.W.; Pearson, T.; Okinaka, R.; Schupp, J.M.; Gillece, J.D.; Heaton, H.; Birdsell, D.; Hepp, C.; Fofanov, V.; Noseda, R.; et al. A Bacillus anthracis genome sequence from the Sverdlovsk 1979 autopsy specimens. MBio 2016, 7, e01501-e01516. [CrossRef]

14. Braun, P.; Grass, G.; Aceti, A.; Serrecchia, L.; Affuso, A.; Marino, L.; Grimaldi, S.; Pagano, S.; Hanczaruk, M.; Georgi, E.; et al. Microevolution of anthrax from a young ancestor (M.A.Y.A.) suggests a soil-borne life cycle of Bacillus anthracis. PLoS ONE 2015, 10, e0135346. [CrossRef] [PubMed]

15. Thümen, F. Herbarium Mycologicum Oeconomicum: [die für Land-, Forst- und Hauswirthschaft, den Gartenbau und die Industrie schädlichen resp. nützlichen Pilze in getrockneten Exemplaren]; Fasc. 14, No. 651-700; IndExs Exsiccatae ID 307188034; Thümen, F von: Vienna, Austria, 1879.

16. Bankevich, A.; Nurk, S.; Antipov, D.; Gurevich, A.A.; Dvorkin, M.; Kulikov, A.S.; Lesin, V.M.; Nikolenko, S.I.; Pham, S.; Prjibelski, A.D.; et al. SPAdes: A new genome assembly algorithm and its applications to single-cell sequencing. J. Comput. Biol. 2012, 19, 455-477. [CrossRef] [PubMed]

17. Walker, B.J.; Abeel, T.; Shea, T.; Priest, M.; Abouelliel, A.; Sakthikumar, S.; Cuomo, C.A.; Zeng, Q.; Wortman, J.; Young, S.K.; et al. Pilon: An integrated tool for comprehensive microbial variant detection and genome assembly improvement. PLoS ONE 2014, 9, e112963. [CrossRef] [PubMed]

18. Li, H.; Durbin, R. Fast and accurate long-read alignment with Burrows-Wheeler transform. Bioinformatics 2010, 26, 589-595. [CrossRef] [PubMed] 
19. Li, H.; Handsaker, B.; Wysoker, A.; Fennell, T.; Ruan, J.; Homer, N.; Marth, G.; Abecasis, G.; Durbin, R. The sequence alignment/map format and SAMtools. Bioinformatics 2009, 25, 2078-2079. [CrossRef]

20. Treangen, T.J.; Ondov, B.D.; Koren, S.; Phillippy, A.M. The Harvest suite for rapid core-genome alignment and visualization of thousands of intraspecific microbial genomes. Genome Biol. 2014, 15, 524. [CrossRef]

21. Tamura, K.; Nei, M. Estimation of the number of nucleotide substitutions in the control region of mitochondrial DNA in humans and chimpanzees. Mol. Biol. Evol. 1993, 10, 512-526.

22. Kumar, S.; Stecher, G.; Tamura, K. MEGA7: Molecular Evolutionary Genetics Analysis version 7.0 for bigger datasets. Mol. Biol. Evol. 2016, 33, 1870-1874. [CrossRef]

23. Van Ert, M.N.; Easterday, W.R.; Huynh, L.Y.; Okinaka, R.T.; Hugh-Jones, M.E.; Ravel, J.; Zanecki, S.R.; Pearson, T.; Simonson, T.S.; U'Ren, J.M.; et al. Global genetic population structure of Bacillus anthracis. PLoS ONE 2007, 2, e461. [CrossRef]

24. Lienemann, T.; Beyer, W.; Pelkola, K.; Rossow, H.; Rehn, A.; Antwerpen, M.; Grass, G. Genotyping and phylogenetic placement of Bacillus anthracis isolates from Finland, a country with rare anthrax cases. BMC Microbiol. 2018, 18, 102. [CrossRef] [PubMed]

(C) 2020 by the authors. Licensee MDPI, Basel, Switzerland. This article is an open access article distributed under the terms and conditions of the Creative Commons Attribution (CC BY) license (http://creativecommons.org/licenses/by/4.0/). 